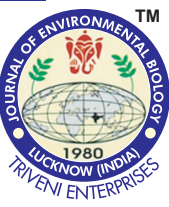

\title{
Reduction in Omega- 6 to Omega 3 ratio and improvement in blood lipid profiles in flaxseed fed Hanwoo steer and human
}

\begin{tabular}{lll}
\hline Paper received: 25.10 .2018 & Revised received: 18.02 .2019 & Re-revised received: 13.03 .2019 \\
\hline
\end{tabular}

\section{Authors Info \\ Y.H. Song, J.S. Kin, K.H. Um, H.J. Park, Y.S. Chol, H.S. Lee, B.S. Park* and J.S. Shin \\ College of Animal Life Science, Kangwon National University, Chuncheon, Gangwondo-200 190, South Korea}

*Corresponding Author Email : bspark@kangwon.ac.kr

\section{Edited by \\ Dr. C.S.K. Mishra}

Reviewed by

Dr. J. Ebanasar

Dr. R.B. Raizada

\section{Abstract}

Aim : To determine the effect of feeding flaxseed on Omega- 6 to Omega-3 ratio $(n-6 / n-3)$ in Korean native steers (Hanwoo) and effect of flaxseed-fed beef consumption on reducing blood lipid profile and glucose in normal human.

Methodology : A total of 60 Hanwoo steers $(750 \mathrm{~kg}$ b.wt.) were assigned three treatments $(20 \mathrm{per}$ treatment). Each treatment group was divided into $\mathrm{C}$ (control, feeding basal diets without flaxseed for 40 days before slaughter), FS5 (feeding 5\% flaxseed for 60 days before slaughter), and FS7.4 (feeding $7.4 \%$ flaxseed for 40 days before slaughter). Fatty acid composition from Hanwoow jugular vein and beef loin were analyzed. Clinical trials were carried out to investigate the effect of consumption of flaxseed-fed beef loin on blood lipid profile and glucose in twenty human subjects.

Results : $n-6 / n-3$ ratio in the blood and beef loin of Hanwoo steers were lowered to 2.26 -

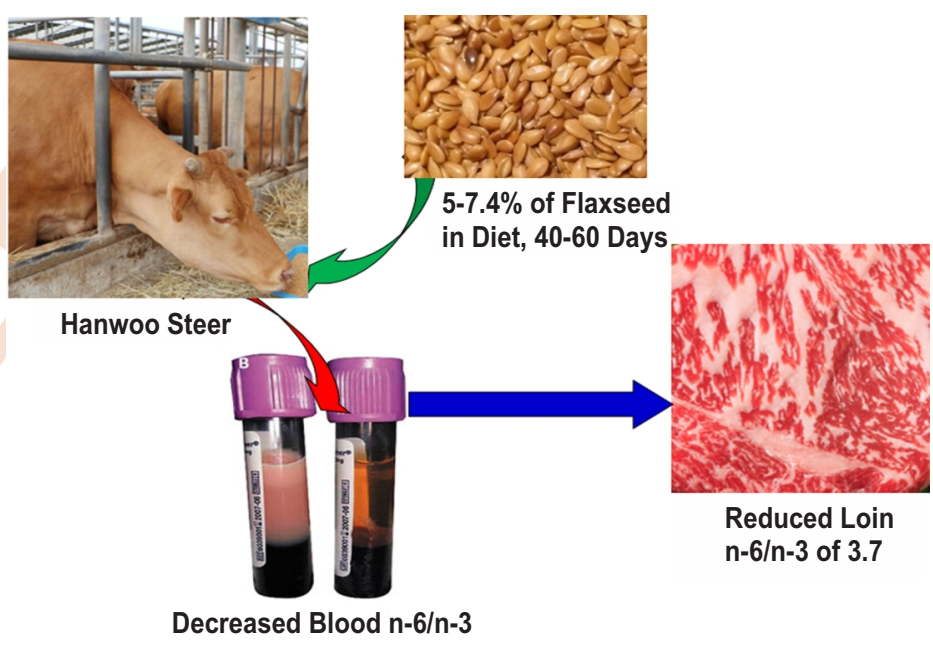

2.27 and 3.67-3.71 in the FS group, respectively, compared with the other groups. Oleic acid level in the blood and beef loin of Hanwoo steers increased to $40.12-42.01$ and $52.27-52.79 \%$, respectively, compared with other groups. Blood triacylglycerol, total cholesterol, and low-density lipoprotein-cholesterol levels in normal human fed with FS beef loin reduced by $25.35,5.22$, and $17.59 \%$, compared to those before intake of beef loin. Blood high density lipoprotein-cholesterol (HDL-C) level in normal human fed with FS beef loin was increased by $6.07 \%$. In human subjects fed with FS and C beef loin, blood glucose level was decreased by 6.42 and $11.82 \%$, respectively.

Interpretation : The results demonstrated that feeding 5 and $7.4 \%$ flaxseed to Hanwoo steers for 40 to 60 days before slaughter could lower n- 6 to n-3 ratio and inhance oleic acid in the blood and beef loin. Further, consumption of flaxseed-fed beef loin by human subjects could improve blood lipid profile.

Key words: Beef loin, Flaxseed, Hanwoo steers, Omega-6/omega-3 fatty acids

How to cite : Song, Y.H., J.S. Kin, K.H. Um, H.J. Park, Y.S. Chol, H.S. Lee, B.S. Park and J.S. Shin: Reduction in Omega-6 to Omega 3 ratio and improvement in blood lipid profiles in flaxseed fed Hanwoo steer and human. J. Environ. Biol., 40, 655-660 (2019). 


\section{Introduction}

As eating habits has evolved into a catering industry or food service industry, including meat, fast food and instant food in Korea, mortality caused by cerebrovascular disease and cardiovascular disease (CVD) ranks second and third, following cancer in humans. As industrialization progresses and cooking oil industry flourishes, excess intake of omega- 6 (n-6), a fatty acid, has emerged as a novel issue (Lands et al., 2018). Excess intake of $n-6$ fatty acid with an increase of omega- 6 to omega-3 fatty acid ratio $(n-6 / n-3)$ and their excess metabolites are linked to metabolic disorder, CVD, inflammation, carcinogenesis, obesity, type 2 diabetes, autoimmune diseases, and depressive disorder. It can also cause considerable harm to bones and general health conditions (Berger et al., 2017). Due to the introduction of Western diet in Korea, intake of n-6 fatty acid has increased over time while the intake of $n-3$ fatty acid has largely decreased (Wijendran and Hayes, 2004), which has resulted in the current ratio of 15:1 to 30:1 (Simopoulos, 2009), against ideal ratio of 4:1 (Husted and Bouzinova, 2016).

Since $n-6$ and $n-3$ fatty acids tend to accumulate in the blood and tissues, it is critically important to maintain a balance between n-6 and n-3 in food to maintain proper health (Calder, 2012; Scaioli et al., 2017). Although there is a minor difference between $n-6$ and $n-3$ in terms of molecular structure, biochemical metabolism and physiological function of these fatty acids are similar to each other. In addition, these two substances compete with each other for same enzyme in the metabolic pathway that features a non-reciprocal conversion (Gogus and Smith, 2010). In animal tissues, accumulation of $n$ 3 fatty acids mainly rely on formulation of fatty acids of the diet (Bou et al., 2005). n-6 fatty acid is rich in animals, and the grainfed beef whose $n-3$ fatty acid is low can have a possibility of increased $n-6 / n-3$ ratio with respect to those of the grass-fed beef (Legrand et al., 2010).

Some studies have reported methods to produce chicken (Ibrahim et al., 2018), pork (Yang and Lien, 2016) and beef diets (McNiven et al., 2011) by adjusting their $n-6 / n-3$ ratio. However, little information is available on the production of Hanwoo beef (FS beef) with lower $n-6 / n-3$ ratio through clinical trials (Legrand et al., 2010). The $n-6 / n-3$ ratio in corn is $46 / 1$. The $n-6 / n-3$ ratio in products of livestock fed with corn-centered feeds is also very high at 6:1 to $15 / 1$ (Simopoulos, 2009). Since Korean dairy farmers who are engaged in the livestock industry mainly feed grain-centered assorted feed such as corn and soybean cake to produce livestock, $n-6 / n-3$ ratios in these animals are similar to those fed with Western diet. It is well known that flaxseeds are rich in n-3 fatty acid and can lower blood lipids in both human and animals, thus reducing chancees of CVD (Legrand et al., 2010). The objective of this study was to determine the effect of feeding flaxseeds on $n-6 / n$ 3 ratio in blood and beef loin of Korean native steers (Hanwoo) and examine the effect of consumption of flaxseed-fed beef loin on blood lipid profiles and glucose in human subjects.

\section{Materials and Methods}

Experimental design and feeding management of animals: $A$ total of 60 Hanwoo steers (750 kg b.wt.) that had attained the end of fattening period were assigned into three treatment groups (20 number per treatment group) using a completely randomized block design. Each treatment group was divided into C (control, feeding basal diets without flaxseed for 40 days before slaughter), FS5 (feeding $5 \%$ flaxseed for 60 days before slaughter) and FS7.4 (feeding $7.4 \%$ flaxseed for 40 days before slaughter). Hanwoo were fed with $8 \mathrm{~kg}$ of daily concentrates and $1 \mathrm{~kg}$ of rice straw as roughages. Concentrate as basal diets was fed a $4 \mathrm{~kg}$ each at 6:00 am and 5:00 pm. FS diets contained 5 or $7.4 \%$ flaxseed in basal diets. Compositions of fatty acids in basal diets, Fs5 and FS7.4 experimental diets were: $n-6 / n-3$ ratio, $12.23,0.78$ and 0.72 ; unsaturated fatty acids, $33.47,53.54$, and $55.43 \%$; and saturated fatty acids, $66.53,46.45$ and $44.58 \%$, respectively. This study was approved by Kangwon National University Animal Experimental Ethics Committee (Approval No. 016-017) and Bioethics Committee (Approval No. 016-35)

Collection of blood samples : Blood sample was randomly collected from Hanwoo of each treatment group on both the commencing date and end of experiment. Blood $(3 \mathrm{ml})$ was collected from each subject animal from their jugular vein using a heparin-treated syringe. Plasma was separated from the collected blood after $15 \mathrm{~min}$ of centrifugation at 3,000 rpm and frozen immediately with liquid nitrogen at $-196^{\circ} \mathrm{C}$. These frozen plasma samples were stored at $-20^{\circ} \mathrm{C}$ for biochemical analyses.

Fatty acid analysis: Beef loin was prepared from 10 Hanwoo per treatment group following slaughter and one $\mathrm{kg}$ per head was gathered. The loin was then cut into small pieces using a meat chopper. Three parts were randomly selected from chopped meat and used for fatty acid analysis (three repetitions for one loaf of loin). Lipid extracted from beef loin and plasma using chloroform and methanol mixture was saponified using $0.5 \mathrm{~N}$ methanolic $\mathrm{NaOH}$ solution. Methylation was carried out using BF3-methanol. Then, $2 \mu$ of supernatant was taken out and injected into a GC (model GC-15A, Shimadzu Corp., Kyoto, Japan) with a SP ${ }^{\mathrm{TM}}$ 2560 Capillary GC Column (LxI.D. $100 \mathrm{~m} \times 0.25 \mathrm{~mm}$, df $0.20 \mu \mathrm{m}$ Omegawax 320 capillary column, Sigma, USA). Supelco (37 component FAME Mix, Sigma-Aldrich Co., St. Louis, MO) was used as a standard solution and nonadecanoic acid (19:0) was used as an internal standard (Park et al., 2010).

Clinical trials: Clinical trial was conducted on 20 college students. They were normal adults. Blood lipid profiles and glucose levels were measured using a Cholestech LDX® System (USA) in these human subjects empty stomach. After excluding 8 subjects who showed difference by a big margin in variation for their triacylglycerol and total cholesterol values, 12 out of these 20 subjects were finally selected. These subjects were informed of the study purpose and necessity of their cooperation before starting the experiment. These were allowed for their usual taste and dietary habits. They subjects were prohibited from eating 
food that might affect their cholesterol level such as drinking or meat eating three days prior to measurement of blood lipid profiles with empty stomach, excluding each and every factor. This trial was repeatedly three times per treatment group (at an interval of 90 days). Blood lipid profiles and glucose levels were measured before and after consumption of beef loin, respectively. In order to measure fasting blood lipid profiles and glucose of subjects prior to consumption of beef loin, subjects were prohibited from eating anything from 12:00 of the night before the consumption to 10:00 in the next morning to keep them hungry. For each subject, $200 \mathrm{~g}$ of beef loin with basal diet was provided. Subjects consumed FS (flaxseed-fed beef, n-6/n-3 lowered Hanwoo beef), $C$ (control beef, feeding basal diets without flaxseed) and GI beef loins (grain-fed imported beef), respectively.

Statistical analyses: The mean and standard deviation of data were computed using IBM SPSS statistics 22 (2013). To determine statistical significance, one-way analysis of variance (ANOVA) with Turkey's multiple range test was performed. Statistical significance of data was set at $95 \%$ level of confidence $(p<0.05)$.

\section{Results and Discussion}

Changes in fatty acid composition in plasma after feeding FS to Hanwoo are shown in Table 1. n-3 fatty acid in the plasma of FS group increased relative to control group at initial days prior to consumption of FS. However, n-6 fatty acid level significantly decreased $(p<0.05)$. The $n-6 / n-3$ ratio in the FS group showed an ideal ratio of less than 4:1 (2.26:1 to 2.78:1) $(p<0.05)$. Palmitoleic acid (16:1n-9) among monounsaturated fatty acids in the FS group significantly decreased compared to control group and at initial days prior to consumption of FS. However, oleic acid $(18: 1 n-9)$ was found to increase significantly $(p<0.05)$. Saturated fatty acid (SFA) showed a decrease in the FS group during this period However, unsaturated fatty acid (UFA) singnificantly increased with increase in UFA/SFA $(p<0.05)$. Activation of $\Delta-9$ desaturase in biohydrogenation and adipose tissues of rumen microorganisms (Park, and Yu, 1994; Gogus and Smith, 2010) might be the probable reason why fatty acids in the blood and $n-$ $6 / n-3$ ratio decreased despite of high $n-6 / n-3$ fatty acid and palmitoleic acid in the diet. It might also be the reason why oleic acid content in the blood increased despite a low figure of this substance in the diet. Rumen microorganisms can change cis unsaturated fatty acids into trans fats and saturated fatty acids via hardening in vivo and activation of $\Delta-9$ desaturase could compose oleic acid from stearic acid (Raes et al., 2001).

Changes in composition of fatty acids of beef loin after feeding FS to Hanwoo are shown in Table 2. n-3 fatty acid of beef loins in the FS group increased significantly compared to that in other groups $(p<0.05)$. However, $n-6$ fatty acid in beef loins of FS group was not significantly different from that in other groups. The $n-6 / n-3$ ratio in the beef of FS group was significantly lower than that of grain-fed control and imported beef $(p<0.05)$. Oleic acid in the FS group was significantly higher than that in the grain-fed control and imported beef. The difference between control and

Table 1: Effect of flax seed on fatty acid composition in plasma of Hanwoo steers according to feeding days (\% of total fatty acids)

\begin{tabular}{|c|c|c|c|c|c|}
\hline \multirow{2}{*}{$\begin{array}{l}\text { Common } \\
\text { formula }\end{array}$} & \multirow{2}{*}{$\begin{array}{l}\text { Common } \\
\text { name }\end{array}$} & \multirow{2}{*}{$\begin{array}{l}\text { Control } \\
\text { group }\end{array}$} & \multicolumn{3}{|c|}{ FS groups ${ }^{1}$} \\
\hline & & & Initial & 40 days & 60 days \\
\hline 8:0 & Octanoic acid & $0.52 \pm 0.24^{2 c}$ & $1.88 \pm 0.42^{\mathrm{a}}$ & $1.61 \pm 0.15^{\mathrm{ab}}$ & $1.33 \pm 0.21^{b}$ \\
\hline 10:0 & Decanoic acid & $1.78 \pm 0.33^{b}$ & $1.32 \pm 0.11^{\mathrm{c}}$ & $1.58 \pm 0.27^{b c}$ & $2.23 \pm 0.30^{\mathrm{a}}$ \\
\hline $12: 0$ & Lauric acid & $2.05 \pm 0.16^{b}$ & $1.81 \pm 0.01^{b}$ & $3.18 \pm 0.06^{a}$ & $3.26 \pm 0.12^{\mathrm{a}}$ \\
\hline $14: 0$ & Myristic acid & $1.07 \pm 0.21^{b}$ & $0.73 \pm 0.17^{b}$ & $1.68 \pm 0.09^{\mathrm{a}}$ & $1.27 \pm 0.07^{\mathrm{a}}$ \\
\hline $16: 0$ & Palmitic acid & $2.01 \pm 0.27^{b}$ & $0.94 \pm 0.11^{\mathrm{c}}$ & $16.74 \pm 0.39^{\mathrm{a}}$ & $16.87 \pm 0.40^{a}$ \\
\hline $16: 1 n-9$ & Palmitoleic acid & $15.14 \pm 0.46^{b}$ & $17.34 \pm 0.81^{\mathrm{a}}$ & $3.46 \pm 0.15^{c}$ & $2.26 \pm 0.31^{\mathrm{d}}$ \\
\hline 18:0 & Stearic acid & $7.15 \pm 0.44^{b}$ & $5.09 \pm 0.40^{c}$ & $17.95 \pm 0.34^{\mathrm{a}}$ & $18.01 \pm 0.28^{a}$ \\
\hline $18: 1 n-9$ & Oleic acid & $24.52 \pm 0.53^{c}$ & $26.58 \pm 0.36^{b}$ & $40.12 \pm 1.61^{\mathrm{a}}$ & $42.01 \pm 3.06^{a}$ \\
\hline $18: 2 n-6$ & Linoleic acid & $33.00 \pm 0.61^{\mathrm{a}}$ & $29.07 \pm 0.10^{b}$ & $8.46 \pm 0.60^{\circ}$ & $7.94 \pm 0.46^{\circ}$ \\
\hline $18: 3 n-3$ & Linolenic acid & $0.25 \pm 0.17^{b}$ & $0.23 \pm 0.02^{b}$ & $3.04 \pm 0.86^{a}$ & $3.52 \pm 0.38^{\mathrm{a}}$ \\
\hline $20: 0$ & Arachdic acid & $12.51 \pm 0.36^{\mathrm{a}}$ & $14.02 \pm 0.43^{\mathrm{a}}$ & $2.18 \pm 0.20^{b}$ & $1.30 \pm 0.29^{b}$ \\
\hline 22:0 & Behenic acid & - & - & - & - \\
\hline $22: 1$ & Erucic acid & - & - & - & - \\
\hline $24: 0$ & Lignoceric acid & - & - & - & - \\
\hline $\mathrm{SFA}^{3}$ & - & $47.09 \pm 0.78^{\mathrm{a}}$ & $45.78 \pm 1.07^{b}$ & $43.92 \pm 0.63^{b}$ & $44.27 \pm 0.84^{b}$ \\
\hline$U A^{4}$ & - & $52.91 \pm 0.55^{\mathrm{b}}$ & $54.22 \pm 0.25^{\mathrm{a}}$ & $55.08 \pm 0.51^{\mathrm{a}}$ & $55.73 \pm 0.61^{\mathrm{a}}$ \\
\hline$n-6 / n-3$ & - & $132.7 \pm 0.52^{\mathrm{a}}$ & $126.4 \pm 0.37^{b}$ & $2.78 \pm 0.05^{c}$ & $2.26 \pm 0.09^{\circ}$ \\
\hline UFA/SFA & - & $1.12 \pm 0.02^{b}$ & $1.18 \pm 0.05^{b}$ & $1.25 \pm 0.07^{\mathrm{a}}$ & $1.26 \pm 0.02^{\mathrm{a}}$ \\
\hline
\end{tabular}

${ }^{1} \mathrm{FS}$ groups: 40 days $\left(7.4 \%\right.$ flaxseed-fed), 60 days ( $5 \%$ flaxseed-fed). ${ }^{2}$ Standard deviation of mean values $(n=10) .{ }^{3}$ SFA: saturated fatty acid. ${ }^{4} U F A$ : unsaturated fatty acid. ${ }^{\text {a.b.c }}$ Mean values with different superscripts differ significantly $(p<0.05)$ 
Table 2 : Fatty acid composition of flaxseed-fed beef (FS) beef loin (\% of total fatty acids) ${ }^{1}$

\begin{tabular}{llllll}
\hline Common formula & Common name & Control beef & GI beef & FS5 & FS7.4 \\
\hline $8: 0$ & Octanoic acid & $0.75 \pm 0.062^{\mathrm{a}}$ & $0.13 \pm 0.02^{\mathrm{b}}$ & $0.19 \pm 0.03^{\mathrm{b}}$ & - \\
$10: 0$ & Decanoic acid & $0.76 \pm 0.03^{\mathrm{a}}$ & $0.12 \pm 0.05^{\mathrm{b}}$ & $0.12 \pm 0.08^{\mathrm{b}}$ & $0.21 \pm 0.18^{\mathrm{b}}$ \\
$12: 0$ & Lauric acid & $0.12 \pm 0.03$ & $0.13 \pm 0.04$ & $0.14 \pm 0.05$ & $0.25 \pm 0.25$ \\
$14: 0$ & Myristic acid & $3.86 \pm 0.71$ & $3.83 \pm 0.27$ & $3.27 \pm 1.16$ & $3.41 \pm 0.55$ \\
$16: 0$ & Palmitic acid & $27.13 \pm 0.84^{\mathrm{a}}$ & $27.62 \pm 1.71^{\mathrm{a}}$ & $26.30 \pm 0.70^{\mathrm{b}}$ & $25.07 \pm 1.31^{\mathrm{c}}$ \\
$16: 1 \mathrm{n}-9$ & Palmitoleic acid & $6.68 \pm 0.91^{\mathrm{a}}$ & $4.95 \pm 0.84^{\mathrm{c}}$ & $5.74 \pm 1.07^{\mathrm{b}}$ & $5.86 \pm 0.56^{\mathrm{b}}$ \\
$18: 0$ & Stearic acid & $9.45 \pm 0.73^{\mathrm{b}}$ & $13.26 \pm 0.30^{\mathrm{a}}$ & $9.32 \pm 1.90^{\mathrm{b}}$ & $9.07 \pm 1.67^{\mathrm{b}}$ \\
$18: 1 \mathrm{n}-9$ & Oleic acid & $50.67 \pm 0.84^{\mathrm{b}}$ & $47.97 \pm 0.36^{\mathrm{c}}$ & $52.27 \pm 1.30^{\mathrm{a}}$ & $52.79 \pm 1.54^{\mathrm{a}}$ \\
$18: 2 \mathrm{n}-6$ & Linoleic acid & $1.88 \pm 0.36$ & $2.01 \pm 0.53$ & $2.19 \pm 0.45$ & $2.24 \pm 0.30$ \\
$18: 3 \mathrm{n}-3$ & Linolenic acid & $0.08 \pm 0.12^{\mathrm{b}}$ & $0.09 \pm 0.03^{\mathrm{b}}$ & $0.59 \pm 0.35^{\mathrm{a}}$ & $0.61 \pm 0.13^{\mathrm{a}}$ \\
$20: 0$ & Arachdic acid & $0.05 \pm 0.01^{\mathrm{c}}$ & $0.01 \pm 0.00^{\mathrm{c}}$ & $0.56 \pm 0.14^{\mathrm{b}}$ & $0.71 \pm 0.11^{\mathrm{a}}$ \\
$22: 0$ & Behenic acid & - & - & - & - \\
$22: 1$ & Erucic acid & - & - & - & - \\
$24: 0$ & Lignoceric acid & - & - & $39.45 \pm 0.57^{\mathrm{b}}$ & - \\
SFA & - & $40.73 \pm 0.51^{\mathrm{b}}$ & $44.99 \pm 0.34^{\mathrm{a}}$ & $60.45 \pm 0.29^{\mathrm{b}}$ & $61.31 \pm 0.47^{\mathrm{a}}$ \\
UFA & - & $59.27 \pm 0.38^{\mathrm{b}}$ & $55.01 \pm 0.25^{\mathrm{c}}$ & $3.71 \pm 0.10^{\mathrm{c}}$ & $3.67 \pm 0.07^{\mathrm{c}}$ \\
$\mathrm{n}-6 / \mathrm{n}-3$ & - & $23.50 \pm 0.78^{\mathrm{a}}$ & $22.33 \pm 0.65^{\mathrm{a}}$ & $1.53 \pm 0.03^{\mathrm{a}}$ & $1.60 \pm 0.08^{\mathrm{a}}$ \\
UFA/SFA & - & $1.46 \pm 0.06 \mathrm{a}^{\mathrm{b}}$ & $1.22 \pm 0.07^{\mathrm{b}}$ & & \\
\hline
\end{tabular}

${ }^{1}$ Control beef : grain-fed Hanwoo beef loin, GI beef: grain-fed imported beef loin, FS5: 5\% flaxseed-fed beef, FS7.4: 7.4\% flaxseed-fed beef. ${ }^{2}$ Standard deviation of the mean values $(n=10)$. ${ }^{3}$ SFA: saturated fatty acid. ${ }^{4} U F A$ : unsaturated fatty acid. ${ }^{\text {a.b.c }}$ Mean values with different superscripts differ significantly $(p<0.05)$

imported beef, both of which took in grain diet, was significant $(p<$ 0.05). However, there was no statistical difference between FS5 and FS7.4. Saturated fatty acid content in imported beef was highest. It showed no significant difference between control beef and FS5, while it was significantly lower in FS7.4 ( $p<0.05)$. Unsaturated fatty acid in FS7.4 was highest, followed by FS5 and control beef. The imported beef had significantly lower content of unsaturated fatty acid $(p<0.05)$, however, there was no significant difference between control beef and FS5.

The reason why n-3 fatty acid and oleic acid in the loin of FS groups were higher than control beef and the imported beef while their $n-6 / n-3$ ratio was significantly lower due to high intake of $n-3$ fatty acid from flaxseeds and the action of rumen microorganisms, as well as distribution channel of imported beef. For control, beef produced with feed concentrates, it is known that $\mathrm{n}-6$ fatty acid provided from the diet is high while n-3 fatty acid is low (Raes et al., 2001). For imported beef, a livestock product that is also produced from concentrates, $n-6$ fatty acid might also be higher than its $n-3$ fatty acid. Because the rate of reduction of $n-3$ fatty acid is much more accelerated than that of $n-6$ fatty acid due to long distribution channel of import and longer duration (Raes et al., 2001). With regard to both n-3 fatty acid and oleic acid accumulated in the loin of Grades 1 to 5 beef (that is, $1^{++}, 1+, 1,2$, and 3 of Hanwoo beef), the values obtained in this study were higher than those reported by Lee et al. (2010). The contents of $n$ 3 fatty acid in the study of Lee et al. (2010) in these five grades were $0.14,0.07,0.05,0.30$ and $0.03 \%$ and those of oleic acid were $53.10,51.54,51.85,49.79$, and $47.40 \%$, respectively. It is known that oleic acid can increase the taste and favor of beef by increasing its marbling attribute. As a consequence, it can function as a fatty acid that can lead to premium meat because it can increase preference of consumers and simultaneously lower blood lipids (Anderson et al., 1975; Lunt and Smith, 1991; Raes et al., 2001). Park and Yu (1994) reported that the qualitative superiority of Hanwoo beef is due to significantly higher oleic acid compared to imported beef. Such excellence is also attributable to the extension of distribution channel while imported beef involves long distribution days (Park and Yu, 1994).

In the present study, the Hanwoo steers fed with FS had lower $n-6 / n-3$ but higher oleic acid in its loin, which is likely due to the action of $\Delta-9$ desaturase. Cow's adipose tissues can synthesize oleic acids from stearic acid (18:0) via unsaturation of $\Delta-9$ desaturase by stearyl Co-A desaturase genes and accumulation of oleic acids in its loin to strengthen the marveling of beef, thus producing high-quality premium meat (May et al., 1993; Smith et al., 2006). As shown in Table 1, despite a high level of stearic acid, stearic acid accumulated in Hanwoo beef loin decreased while oleic acid was increased. Due to the metabolism of $\Delta-9$ desaturase mentioned above. It is well known that Japanese Wagyu beef and American Aberdeen Angus beef contain high levels of oleic acid accumulated in their loins. Changes in blood lipid profile and glucose levels in human subjects after consumption of FS (flaxseed-fed beef, n-6/n-3 lowered Hanwoo beef), C (control beef fed basal diets without flaxseed) or $\mathrm{Gl}$ (grain-fed imported beef) loins are illustrated in Fig. 1. Blood triacylglycerol (TAG) level significantly reduced 

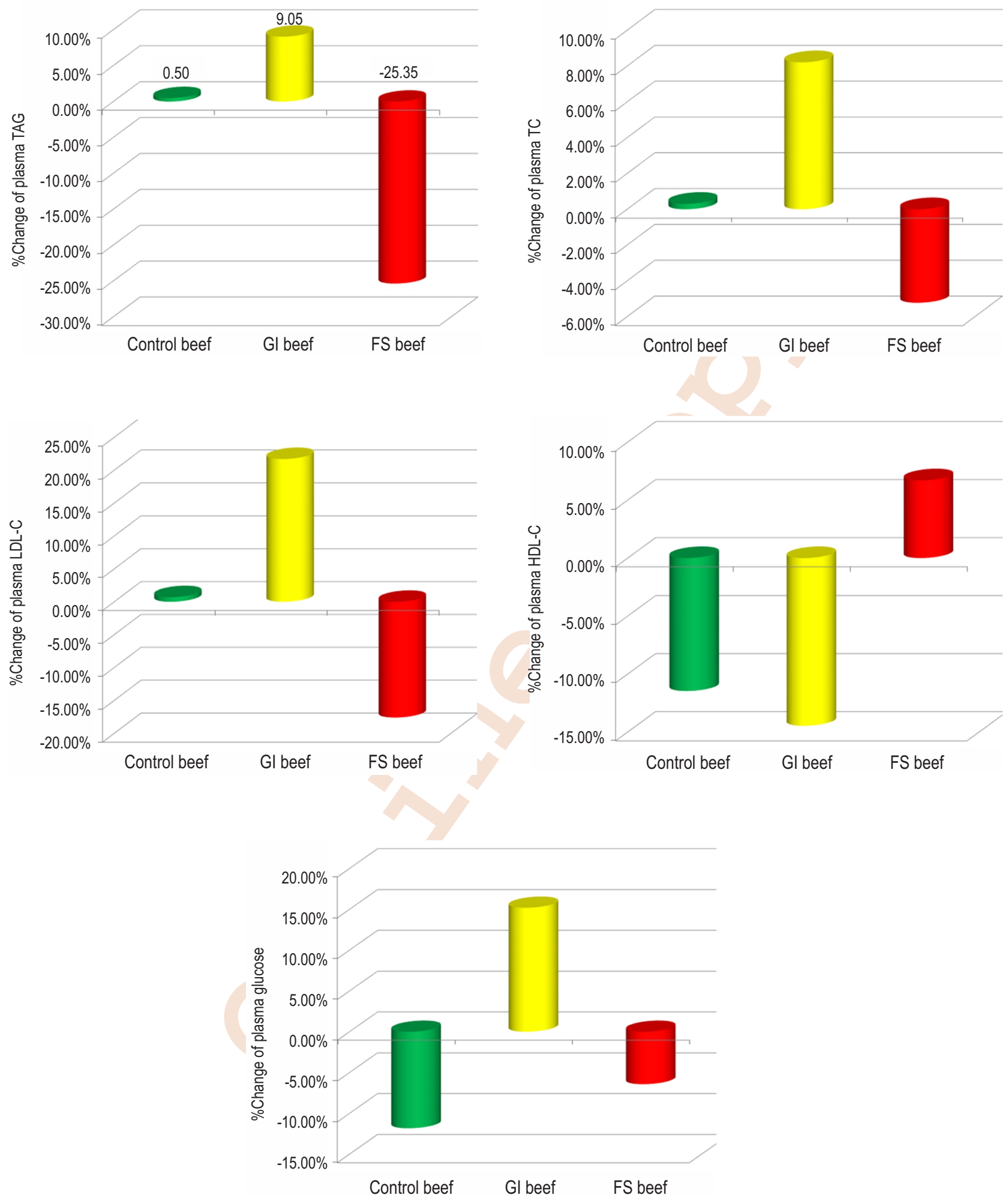

Fig. 1 : Effects of flaxseed-fed beef loin (FS) on changes of blood lipid profiles and glucose in human subjects by clinical trials. Control beef : grain-fed Hanwoo beef loin, GI beef : grain-fed imported beef loin, FS beef : flaxseed-fed beef loin (n-6/n-3 lowered Hanwoo), TAG: triacylglycerol, TC: total cholesterol, LDL-C: low density lipoprotein-cholesterol, HDL-C: high density lipoprotein-cholesterol. 
$(25.35 \%, p<0.05)$ in subjects fed with FS beef loin. However, those fed $\mathrm{Gl}$ beef loin, it was further increased by $9.05 \%$. Consumption of control beef loin did not change TAG level significantly. Total cholesterol level decreased by $5.22 \%$ in human subjects fed with FS beef loin while subjects fed GI beef loin was significantly increased by $8.21 \%(p<0.05)$. Control beef loin did not lead to significant difference in total cholesterol level. Low density lipoprotein-cholesterol (LDL-C) significantly decreased by $17.59 \%$ in subjects fed with FS beef loin. However, it increased by $21.70 \%$ in subjects fed with $\mathrm{GI}$ beef loin $(p<0.05)$. It showed no different appreciable change in subjects fed with control beef loin. High density lipoprotein-cholesterol (HDL-C) increased by $6.07 \%$ in subjects fed with FS beef loin. However, in human subjects fed with $\mathrm{Gl}$ beef and control beef, it significantly decreased by 14.46 and $11.46 \%$, respectively $(p<0.05)$. Blood glucose levels in human subjects fed FS beef and control beef were significantly decreased by 6.42 and $11.82 \%$, respectively. However, subjects fed with $\mathrm{Gl}$ beef, it was increased by $15.19 \%(p<0.05)$.

Intake of food high in $n-6 / n-3$ ratio could raise the level of LDL-C in the blood and lead to CVD (Simopoupos, 2000; German and Dillard, 2004). LDL is the most important carrier that transports cholesterol from liver to blood. Cholesterol then accumulates in arteries and cells of epithelial tissues of the body. On the contrary, $\mathrm{HDL}-\mathrm{C}$ can reverse transport cholesterol from the blood to the liver and release it into excrements after biligenesis. Cholesterol then passes through the digestive tract, eventually being removed from the blood (Daley et al., 2010; Riediger et al., 2009). The finding of this study is very important for producing beef with lower n-6 / n-3 ratio while enhancing oleic acid by feeding flaxseed to Hanwoo steers to reduce blood lipid profiles and glucose in humans after consuming flaxseed-fed beef.

\section{Acknowledgment}

This research was supported by the Ministry of Agriculture, Food and Rural Affairs (C1010613-01-03), Republic of Korea.

\section{References}

Anderson, B.A., J.A. Kinsella and B.K. Watt: Comprehensive evaluation of fatty acids in foods. II. Beef products. J. Am. Diet. Assoc., 67, 3541 (1975).

Berger, M.E., S. Smesny, S.W. Kim, C.G. Davey, S. Rice, Z. Sarnyai, M. Schlögelhofer, M.R. Schäfer, M. Berk, P.D. McGorry and G.P. Amminger: Omega-6 to omega-3 polyunsaturated fatty acid ratio and subsequent mood disorders in young people with at-risk mental states: a 7-year longitudinal study. Transl. Psychiatry, 7,e1220; doi:10.1038/tp.2017.190 (2017).

Bou, R., F. Guardiola, A.C. Barroeta and R. Codony: Effect of dietary fat sources and zinc and selenium supplements on the composition and consumer acceptability of chicken meat. J. Poult. Sci., 84, $1129-1140(2005)$

Calder, P.C. : Mechanisms of action of (n-3) fatty acids. The J. Nutrition., $142,592 S-599 S(2012)$
German, J.B. and C.H. Dillard: Saturated fats: What dietary intake? Am. J. Clin. Nutr., 80, 550-559 (2004).

Gogus, U. and C. Smith: n-3 Omega fatty acids: A review of current knowledge. Int. J. Food Tech., 45, 417-436 (2010).

Husted, K.S. and E.V. Bouzinova: Review, the importance of n-6/n-3 fatty acids ratio in the major depressive disorder. Medicina, 52, 139-147 (2016)

Ibrahim, D., R. El-Sayed, S.I. Khater, E.N. Said and S.A.M. El-Mandrawy: Changing dietary n-6:n-3 ratio using different oil sources affects performance, behavior, cytokines mRNA expression and meat fatty acid profile of broiler chickens. Anim. Nutr., 4, 44-51 (2018).

Lands, B., D. Bibus and K.D. Stark: Dynamic interactions of $n-3$ and n-6 fatty acid nutrients, prostaglandins, leukotrienes and essential fatty acids. PLEFA, 136, 15-21 (2018).

Lee, Y.J., C.H. Kim, J.H. Kim, B.Y. Park, P.N. Seong, G.H. Kang, D.H. Kim and S.H. Cho: Comparison of fatty acid composition of Hanwoo beef by different quality grades and cuts. Kor. J. Food Sci. Ani. Resour., 30, 110-119(2010).

Legrand, P., B. Schmitt, J. Mourot and D. Catheline: The consumption of food products from linseed-fed animals maintains erythrocyte omega-3 fatty acids in obese humans. Lipids, 45, 11-19 (2010).

Lunt, D.K. and S.B. Smith: Wagyu beefs holds profit potential for US. Feedlot. Feedstuffs, 19, 18-19 (1991).

May, S.G., C.A. Stordivant, D.K. Lunt, R.K. Miller and S.B. Smith: Comparison of sensory characteristics and fatty acid composition between Waygu cross-breeds and Angus steers, Meat Sci., 35, 289-298 (1993).

McNiven, M.A., J.K. Duynisveld, T. Turner and A.W. Mitchell: Ratio of n-6/n3 in the diets of beef cattle: Effect on growth, fatty acid composition, and taste of beef. Anim. Feed Sci. Tech., 170, 171-181 (2011).

Park, B.S. and I.J. Yu: Comparison of fatty acid composition among imported beef, Holstein steer beef and Hanwoo beef. J. Anim. Sci. Technol. (Kor.)., 36, 69-75 (1994).

Park, S.O., J. Whangbo, I.S. Yuh and B.S. Park: Gamma-linolenic acid egg production enriched with hemp seed oil and evening primrose oil in diet of laying hens. J. Environ. Biol., 35, 635-640 (2010).

Raes, K., S. De Smet and D.I. Demeyer: Effect of double-muscling in Belgian blue young bulls on the intramuscular fatty acid composition with emphasis on conjugated linoleic acid and polyunsaturated fatty acids. Anim. Sci., 73, 253-260 (2001).

Riediger, N.D., R.A. Othman and M. Suh: A systematic review of the roles of n-3 fatty acids in health and disease. J. Am. Diet. Assoc., 109, 668-679 (2009).

Scaioli, E., E. Liverani and A. Belluzzi: Review, The imbalance between $n-6 / n-3$ polyunsaturated fatty acids and inflammatory bowel disease: A comprehensive review and future therapeutic perspectives. Int. J. Mol. Sci., 18, 2619-2632 (2017).

Simopoulos, A.P. : Omega-3 fatty acids in health and disease and in growth and development. Am. J. Clin. Nutr., 54, 438-463 (2000).

Simopoulos, A.P. : Evolutionary aspects of the dietary omega-6:omega-3 fatty acid ratio: medical implications. World Rev. Nutr. Diet., 100, 121 (2009).

Smith, S.B., K. David and K.Y. Lunt: Adiposity, fatty acid composition, and delta-9 desaturase activity during growth in beef cattle. Anim. Sci. J., 77, 478-486 (2006).

Wijendran, V. and K.C. Hayes: Dietary n- 6 and n-3 fatty acid balance and cardiovascular health. Annu. Rev. Nutr., 24, 597-615 (2004).

Yang, J.R. and T.F. Lien: Healthy pork production through dietary n6:n3 ratio regulation. J. Agric. Sci., 8, 25-38 (2016). 